\title{
ER $\beta$ overexpression results in endocrine therapy resistance and poor prognosis in postmenopausal ER $\alpha$-positive breast cancer patients
}

\author{
LIYING GUO ${ }^{1}$, YU ZHANG ${ }^{2}$, DILIMINA YILAMU ${ }^{1}$, SHA LIU $^{1}$ and CHENMING GUO ${ }^{1}$ \\ ${ }^{1}$ Department of Breast Cancer, Digestive and Vascular Center, \\ First Affiliated Hospital of Xinjiang Medical University, Urumqi, Xinjiang 830054; ${ }^{2}$ Department of General Surgery, \\ Yantai Affiliated Hospital of Binzhou Medical University, Yantai, Shandong 264100, P.R. China
}

Received December 9, 2014; Accepted October 28, 2015

DOI: $10.3892 / \mathrm{ol} .2016 .4095$

\begin{abstract}
The aim of the present study was to investigate the role of estrogen receptor (ER) $\beta$ in the prognosis of ERa-positive breast cancer in postmenopausal women, and its effect on the efficacy of endocrine therapy. Tissue specimens from 195 patients with postmenopausal breast cancer were analyzed. ER $\beta$ expression levels were detected using immunohistochemical staining. Kaplan-Meier analysis was performed to assess patient survival, and the difference in survival was analyzed using the log-rank test. Cox regression was utilized to evaluate prognostic factors. The results revealed that the disease-free survival rate decreased dramatically as ER $\beta$ expression levels increased in all postmenopausal ER $\alpha$-positive breast cancer patients, and ER $\beta$ expression was identified to be an indicator of poor prognosis in cases of this disease. Similarly, in postmenopausal ER $\alpha$-positive breast cancer patients undergoing endocrine therapy, high ER $\beta$ expression levels reduced the disease-free survival rate and were correlated with poor patient prognosis. However, in such patients who were not treated with endocrine therapy, disease-free survival rate and prognosis were not significantly affected by ER $\beta$ expression. In conclusion, ER $\beta$ overexpression led to endocrine therapy resistance and poor prognosis in postmenopausal ER $\alpha$-positive breast cancer patients, suggesting that ER $\beta$ may affect breast cancer prognosis via an increase in endocrine therapy resistance.
\end{abstract}

Correspondence to: Dr Liying Guo, Department of Breast Cancer, Digestive and Vascular Center, First Affiliated Hospital of Xinjiang Medical University, 137 Liyushan Road, Urumqi, Xinjiang 830054, P.R. China

E-mail: gejsy318@126.com

Key words: postmenopausal breast cancer, estrogen receptor $\beta$, endocrine therapy, resistance

\section{Introduction}

Endocrine-associated types of cancer in humans exhibit gender-specific hormonal responsiveness; for example, androgen responsiveness for prostate cancer in males, and estrogen responsiveness for breast cancer in females (1). As the normal growth of certain tissues (including the prostate and breast) is dependent upon specific hormones, it is reasonable to assume that these hormones may be involved in malignant growth of these organs. Under normal conditions, hormone-stimulated tissue growth is well-modulated and controlled and, even with continuous exposure to hormones, tissues do not undergo unlimited growth (2). Malignant growth of organs in response to hormones may be attributed to upregulated activity of growth signals, or the downregulation of signals that normally inhibit proliferation (2).

Estrogen has a significant role in the occurrence, malignant progression and prognosis of breast cancer (3). Estrogen receptors (ERs) and the genes they regulate have additionally been studied as primary targets in clinical treatment for the control of breast cancer (4). For example, ER $\alpha$ gene expression is a significant event in breast cancer, and its overexpression may be an initiating event in carcinogenesis. However, ER $\beta$ has been identified to be highly expressed in normal and malignant breast tissue $(5,6)$. Previous studies have additionally demonstrated co-expression of ER $\beta$ and ER $\alpha$ in human breast cancer cells (7-9). Expression of ER $\alpha$ is identified in $\sim 60 \%$ of breast cancer tissues, and types of cancer demonstrating this expression are known as ER-dependent (10). The majority of these ER $\alpha$-positive breast cancer cases are sensitive to endocrine therapy; however, $30 \%$ of them demonstrate endocrine therapy resistance (11). Therefore, we hypothesize that ER $\beta$ has become an alternative indicator for the sensitivity of breast cancer to endocrine therapy, and a promising target for the control of tumor growth.

In the present study, immunohistochemical staining was performed to detect the expression levels of ER $\beta$ in postmenopausal ER $\alpha$-positive breast cancers. In addition, the influence of differential ER $\beta$ expression on the efficacy of endocrine therapy, as well as on disease-free survival rate, was analyzed in these patients. The importance of ER $\beta$ in guiding endocrine 
therapeutic strategies for the treatment of breast cancer, and its role in disease prognosis were evaluated to provide a basis for determining maximum benefit in clinical treatment.

\section{Materials and methods}

Patient samples. The clinical inclusion criteria for patient samples were as follows: i) Postmenopausal females with stage I or II breast cancer, according to the 7th edition of the American Joint Committee on Cancer staging manual (12); ii) ERo-positivity on immunohistochemical staining; iii) patient underwent radical or modified radical mastectomy; iv) cancer pathologically confirmed to be infiltrating ductal carcinoma; and v) presence of complete clinical and follow-up data. In total, 207 patients met these criteria and were included in the present study. These patients were diagnosed with breast cancer and surgically treated at the First Affiliated Hospital of Xinjiang Medical University (Urumqi, China), between January 2000 and December 2010. The patients were followed up for 2-12 years. During the follow-up period, 12 patients were censored. Of the 195 patients with effective follow-up, 140 patients were treated with endocrine therapy, whilst 55 patients were not treated with endocrine therapy.

Recurrence diagnosis was based on pathological evidence confirmed by biopsy. Lymph node and distant metastases were detected using CT (computed tomography), ultrasound, X-ray, emission CT or magnetic resonance imaging. Disease-free survival time was calculated from the date of surgery, and recurrence or metastasis was counted on the date of diagnosis thereof.

Prior written and informed consent was obtained from all patients, and the study was approved by the ethical review board of Xinjiang Medical University.

Immunohistochemical staining. Breast cancer tissue specimens were fixed in $10 \%$ formaldehyde for $24 \mathrm{~h}$ and subsequently embedded in paraffin. Tissue specimens were sliced into $3-\mu \mathrm{m}$ sections and placed in a $70^{\circ} \mathrm{C}$ oven overnight. Sections were subsequently dewaxed in xylene (Beijing Zhongshan Golden Bridge Biotechnology Co., Ltd., Beijing, China) for $20 \mathrm{~min}$ and rehydrated in graded alcohols. Endogenous peroxidase activity was blocked using a 3\% solution of hydrogen peroxide (Beijing Zhongshan Golden Bridge Biotechnology Co., Ltd.) for $10 \mathrm{~min}$. For antigen retrieval, sections were placed in EDTA antigen retrieval solution (Beijing Zhongshan Golden Bridge Biotechnology Co., Ltd.) and boiled for $20 \mathrm{~min}$. Following cooling to room temperature and washing with phosphate-buffered saline (PBS; Wuhan Boster Biological Technology, Ltd., Wuhan, China), sections were incubated with polyclonal rabbit anti-human ER $\beta$ primary antibody (cat. no. BY-02101; 1:100; Shanghai Yueyan Biological Technology, Co., Ltd., Shanghai, China), at $37^{\circ} \mathrm{C}$ for $1 \mathrm{~h}$ in the dark. Subsequently, sections were incubated with horseradish peroxidase-conjugated goat anti-rabbit IgG secondary antibodies (cat. no. K500711; 1:200; Shanghai Gene Biological Technology Co., Ltd., Shanghai, China). at $37^{\circ} \mathrm{C}$ for $30 \mathrm{~min}$ in the dark. Following antibody incubation, sections were developed using 3,3'-diaminobenzidine chromogenic reagent (Beijing Zhongshan Golden Bridge Biotechnology Co., Ltd.) for $5 \mathrm{~min}$ and counterstained by hematoxylin
(Beijing Zhongshan Golden Bridge Biotechnology Co., Ltd.). Following hydrochloric acid differentiation and dehydration in graded alcohols, sections were mounted using neutral gum (Beijing Zhongshan Golden Bridge Biotechnology Co., Ltd.). ER $\beta$-positive breast cancer tissue samples served as positive controls. In the negative controls, secondary antibody was replaced by PBS.

Immunohistochemical staining results were evaluated by an experienced pathologist. Cells exhibiting brown staining were classified as ER $\beta$-positive cells. A total of five random high-power fields were evaluated using a Leica DM LB2 microscope (Leica, Wetzlar, Germany). The ER $\beta$-positive rate was the ratio of the number of ER $\beta$-positive cells to the total number of cells in each field. An ER $\beta$-positive rate $<1 \%$ was defined as ER $\beta$-negative [ER $\beta$ (-)]. A positive rate of 1-10\% was defined as ER $\beta$-weak-positive $[\operatorname{ER} \beta(+)]$. An ER $\beta$-positive rate of $11-70 \%$ was defined as ER $\beta$-positive $[\operatorname{ER} \beta(++)]$. An ER $\beta$-positive rate $>70 \%$ was defined as ER $\beta$-strong-positive $[\operatorname{ER} \beta(+++)]$. Expression levels of ER $\alpha$ were classified into the following four categories: $\mathrm{ER} \alpha$-negative $(-),<30 \%$ positive rate; ER $\alpha$-weak-positive (+), 30-40\% positive rate; ER $\alpha$-positive $(++), 40-60 \%$ positive rate; and ER $\alpha$-strong-positive (+++), $>60 \%$ positive rate (13). HER-2 expression levels were defined according to the 2009 HER-2 Detection Guide (14), as follows: HER-2 (-), no staining; HER-2 (+), weak or incomplete cell membrane staining; HER-2 (++), 10-30\% of invasive cancer cells exhibiting weak to moderate, complete but non-uniform membrane staining; HER-2 (++), $>30 \%$ of invasive cancer cells showing strong, complete and uniform membrane staining.

Statistical analysis. SPSS version 17.0 (SPSS, Inc., Chicago, IL, USA) was used for statistical analyses. The rank-sum test was utilized for evaluation of the association between ER $\beta$ expression levels and clinical indices. Disease-free survival rates were calculated using the Kaplan-Meier method. The log-rank test was utilized to compare the disease-free survival rates between groups with varying ER $\beta$ expression levels. Cox regression analysis was performed to assess the influence of ER $\beta$ expression levels and additional clinicopathological indices on the disease-free survival rates of postmenopausal breast cancer patients. $\mathrm{P}<0.05$ was considered to indicate a statistically significant difference.

\section{Results}

ER $\beta$ overexpression decreases the disease-free survival rate and affects the prognosis of postmenopausal patients with ERo-positive breast cancer. In order to investigate the role of ER $\beta$ in the development and progression of breast cancer, the expression levels of ER $\beta$ in ER $\alpha$-positive patients were detected by immunohistochemistry. Representative immunohistochemical results are shown in Fig. 1. Cells exhibiting brown staining were considered ER $\beta$-positive cells. Based on the percentage of $E R \beta$-positive cells, $E R \beta$ expression was divided into four groups: $\operatorname{ER} \beta$ (-) (Fig. 1A), ER $\beta$ (+) (Fig. 1B), ER $\beta$ (++) (Fig. 1C) and $\operatorname{ER} \beta(+++)$ (Fig. 1D). Subsequently, the association between clinicopathological index and ER $\beta$ expression was evaluated. As revealed in Table I, lymph node metastasis, clinical stage, and ER $\alpha$ and HER2 expression levels were not significantly correlated with $\mathrm{ER} \beta$ expression levels $(\mathrm{P}=0.372, \mathrm{P}=0.576, \mathrm{P}=0.578$ 
Table I. Association between clinicopathological indices and ER $\beta$ expression levels in postmenopausal ER $\alpha$-positive breast cancer patients $(\mathrm{n}=195)$, investigated by rank sum test.

\begin{tabular}{lrr}
\hline Clinicopathological features & No. of cases & Mean rank-order \\
\hline Tumor diameter, cm & 100 & 86.85 \\
$\leq 2$ & 95 & 109.74 \\
$>2$ & & \\
Lymph node metastasis & 139 & 95.09 \\
L=0 & 39 & 94.27 \\
1 $<<4$ & 17 & 112.91 \\
L>4 & & \\
Clinical stage & 79 & 95.51 \\
I & 116 & 99.70 \\
II & & \\
ER $\alpha$ expression level & 94 & 95.27 \\
+ & 81 & 98.60 \\
++ & 20 & 108.40 \\
+++ & & 0.576 \\
HER2 expression level & 104 & 91.15 \\
- & 43 & 112.37 \\
+ +++ & 48 & 99.96 \\
+++ & & 0.578 \\
\hline
\end{tabular}

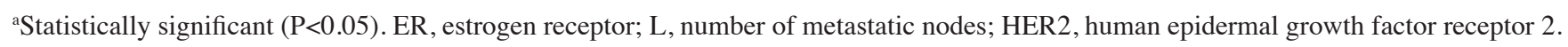

Table II. Analysis of prognostic factors by Cox regression analysis in ER $\alpha$-positive postmenopausal breast cancer patients $(\mathrm{n}=195)$.

\begin{tabular}{lcccccc}
\hline Clinicopathological features & $\beta$ coefficient & SEM & Wald value & P-value & Odds ratio & 95\% CI \\
\hline ER $\beta$ expression level & & & & & & \\
- & $\mathrm{NA}$ & $\mathrm{NA}$ & 14.911 & $0.001^{\mathrm{a}}$ & $\mathrm{NA}$ & $\mathrm{NA}$ \\
$+/++$ & -0.223 & 0.664 & 0.113 & 0.737 & 0.800 & $0.218-2.943$ \\
+++ & 1.529 & 0.447 & 11.699 & $0.001^{\mathrm{a}}$ & 4.612 & $1.921-11.074$ \\
Clinical stage & $\mathrm{NA}$ & $\mathrm{NA}$ & 7.687 & $0.021^{\mathrm{a}}$ & $\mathrm{NA}$ & $\mathrm{NA}$ \\
II & 1.440 & 0.629 & 5.246 & $0.022^{\mathrm{a}}$ & 4.223 & $1.231-14.484$ \\
III & 2.084 & 0.768 & 7.366 & $0.007^{\mathrm{a}}$ & 8.037 & $1.784-36.199$ \\
Chemotherapy & 0.325 & 0.514 & 0.398 & 0.528 & 1.384 & $0.505-3.792$ \\
Radiotherapy & 0.266 & 0.472 & 0.317 & 0.573 & 1.305 & $0.517-3.293$ \\
Endocrine therapy & 0.410 & 0.525 & 0.608 & 0.435 & 1.506 & $0.538-4.217$ \\
\hline
\end{tabular}

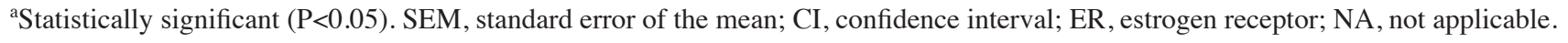

and $\mathrm{P}=0.068$, respectively). By contrast, tumor diameter did demonstrate a significant correlation with ER $\beta$ expression levels $(\mathrm{P}=0.002)$; higher $\mathrm{ER} \beta$ expression levels accompanied greater tumor diameters.

Subsequently, it was investigated whether ER $\beta$ expression affected the disease-free survival rate and prognosis of postmenopausal patients with ER $\alpha$-positive breast cancer. The results demonstrated that ER $\beta$ overexpression significantly decreased the disease-free survival rate in postmenopausal breast cancer patients (log-rank test, 20.277; $\mathrm{P}=0.002$; Fig. 2). Furthermore, Cox regression analysis revealed that neither chemotherapy, radiotherapy or endocrine therapy were independent prognostic factors, while late clinical stage and ER $\beta$ overexpression represented independent prognostic risk factors for postmenopausal breast cancer patients $[\mathrm{P}=0.001$; odds ratio $(\mathrm{OR}),>1$; Table II].

ER $\beta$ overexpression decreases the disease-free survival rate and affects the prognosis of ER $\alpha$-positive postmenopausal 
Table III. Analysis of prognostic factors by Cox regression analysis in postmenopausal ER $\alpha$-positive breast cancer patients treated with endocrine therapy $(n=140)$.

\begin{tabular}{lcccccc}
\hline Clinicopathological features & $\beta$ coefficient & SEM & Wald value & P-value & Odds ratio & 95\% CI \\
\hline ER $\beta$ expression level & & & & & & \\
- & NA & NA & 8.729 & $0.013^{\text {a }}$ & NA & NA \\
$+/++$ & -1.118 & 222.746 & 0.003 & 0.960 & $<0.001$ & $3.502-5.606$ \\
+++ & 1.472 & 0.498 & 8.726 & $0.003^{\text {a }}$ & 4.612 & $1.641-11.570$ \\
Clinical stage & NA & NA & 5.422 & 0.066 & NA & NA \\
II & 1.388 & 0.784 & 3.136 & 0.077 & 4.006 & $0.862-18.612$ \\
III & 2.040 & 0.877 & 5.410 & 0.020 & 7.693 & $1.379-42.937$ \\
Chemotherapy & 0.333 & 0.574 & 0.336 & 0.562 & 1.395 & $0.453-4.295$ \\
Radiotherapy & 0.099 & 0.609 & 0.026 & 0.871 & 1.104 & $0.335-3.642$ \\
\hline
\end{tabular}

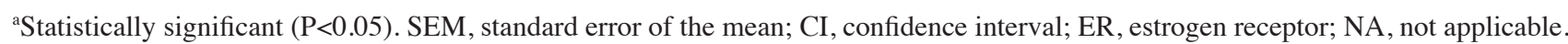

Table IV. Analysis of prognostic factors by Cox regression analysis in postmenopausal ER $\alpha$-positive breast cancer patients not treated with endocrine therapy $(n=55)$.

\begin{tabular}{|c|c|c|c|c|c|c|}
\hline Clinicopathological features & $\beta$ coefficient & SEM & Wald value & P-value & Odds ratio & $95 \% \mathrm{CI}$ \\
\hline \multicolumn{7}{|l|}{ ER $\beta$ expression level } \\
\hline- & NA & NA & 2.001 & 0.368 & NA & NA \\
\hline$+/++$ & 0.372 & 1.194 & 0.097 & 0.756 & 1.450 & $0.140-15.062$ \\
\hline+++ & 1.539 & 1.251 & 1.512 & 0.219 & 4.659 & $0.401-54.123$ \\
\hline Clinical stage & 0.785 & 1.153 & 0.463 & 0.496 & 2.192 & $0.229-20.987$ \\
\hline Chemotherapy & -13.121 & 1076.095 & 0.000 & 0.990 & $<0.001$ & NA \\
\hline Radiotherapy & 0.622 & 0.916 & 0.461 & 0.497 & 1.862 & $0.309-11.223$ \\
\hline
\end{tabular}

SEM, standard error of the mean; CI, confidence interval; ER, estrogen receptor; NA, not applicable.

A

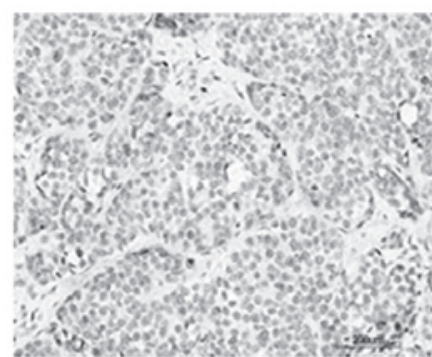

$\operatorname{ER} \beta(-)$

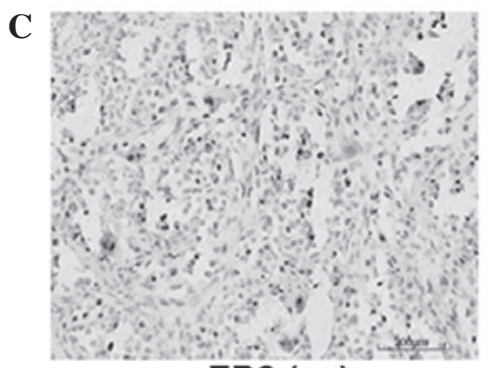

$\operatorname{ER} \beta(++)$
B

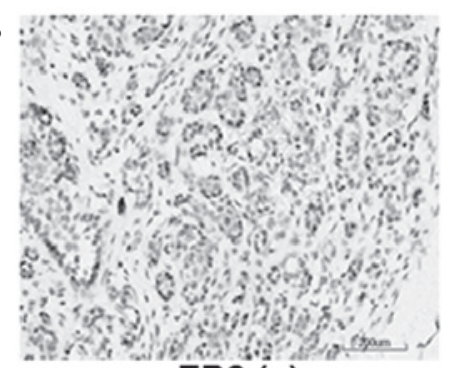

$\operatorname{ER} \beta(+)$

D

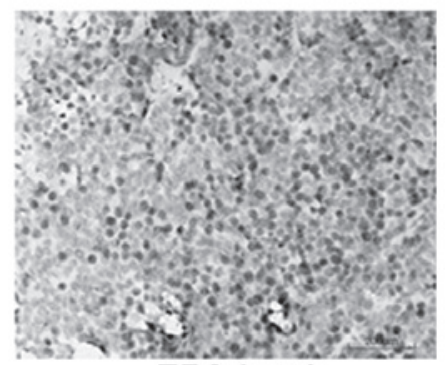

$\operatorname{ER} \beta(+++)$

Figure 1. Expression levels of ER $\beta$ in postmenopausal ER $\alpha$-positive breast cancer patients. Immunohistochemistry was performed to detect the expression levels of ER $\beta$. Representative immunohistochemical results are shown. Cells exhibiting brown staining were classified as ER $\beta$-positive cells. ER $\beta$-positive cells were counted and the ER $\beta$-positive rate was calculated. (A) ER $\beta$ (-), ER $\beta$-positive rate <1\%. (B) ER $\beta$ (+), ER $\beta$-positive rate 1-10\%. (C) ER $\beta$ (++), ER $\beta$ positive rate $10-70 \%$. (D) $\mathrm{ER} \beta(+++), \mathrm{ER} \beta$-positive rate $>70 \%$. ER, estrogen receptor. 


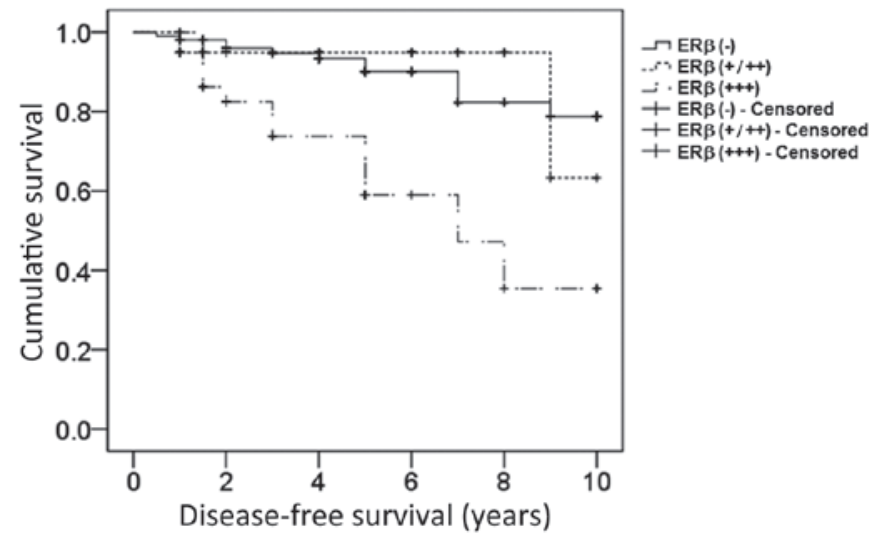

Figure 2. Kaplan-Meier survival curve for postmenopausal ER $\alpha$-positive breast cancer patients exhibiting varying expression levels of ER $\beta$. Disease-free survival was analyzed using the Kaplan-Meier method in 195 patients. An ER $\beta$-positive rate $<1 \%$ was recognized as ER $\beta(-)$, between $1-70 \%$ as $\operatorname{ER} \beta(+/++)$ and $>70 \%$ as $\operatorname{ER} \beta(+++)$. The data from 12 patients were censored due to mortality, loss to follow-up or closure of the study. ER, estrogen receptor.

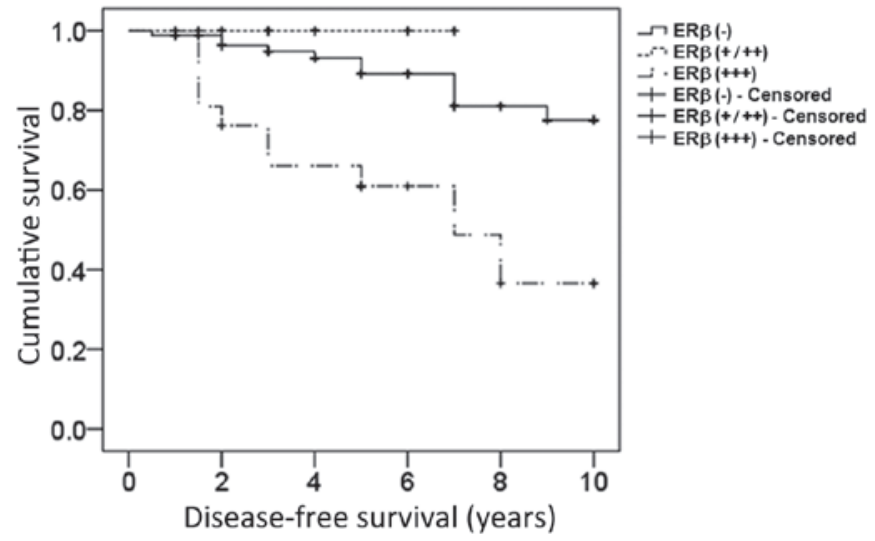

Figure 3. Kaplan-Meier survival curve for endocrine therapy-treated postmenopausal ER $\alpha$-positive breast cancer patients exhibiting varying expression levels of ER $\beta$. Disease-free survival was analyzed using the Kaplan-Meier method in 140 patients. An ER $\beta$-positive rate $<1 \%$ was recognized as $\operatorname{ER} \beta(-)$, between $1-70 \%$ as $\operatorname{ER} \beta(+/++)$ and $>70 \%$ as $\operatorname{ER} \beta(+++)$. The data from 12 patients were censored due to mortality, loss to follow-up or closure of the study. ER, estrogen receptor.

breast cancer patients treated with endocrine therapy. In order to identify whether ER $\beta$ overexpression influenced the therapeutic effects of endocrine therapy, disease-free survival rate and prognosis were assessed in postmenopausal ER $\alpha$-positive breast cancer patients treated with endocrine therapy. As demonstrated in Fig. 3, the upregulated expression of ER $\beta$ significantly decreased the disease-free survival rate in postmenopausal breast cancer patients treated with endocrine therapy (log-rank test, 19.473; $\mathrm{P}=0.003)$. In addition, Cox regression analysis indicated that expression levels of ER $\beta$ were the only independent prognostic factor, with ER $\beta$ overexpression representing the prognostic risk factor $(\mathrm{P}=0.013$; $\mathrm{OR},>1)$, while clinical stage, chemotherapy, and radiotherapy were not independent factors $(\mathrm{P}=0.066, \mathrm{P}=0.562$ and $\mathrm{P}=0.871$, respectively; Table III).

ER $\beta$ expression levels do not affect disease-free survival rate or prognosis in ER $\alpha$-positive postmenopausal breast cancer

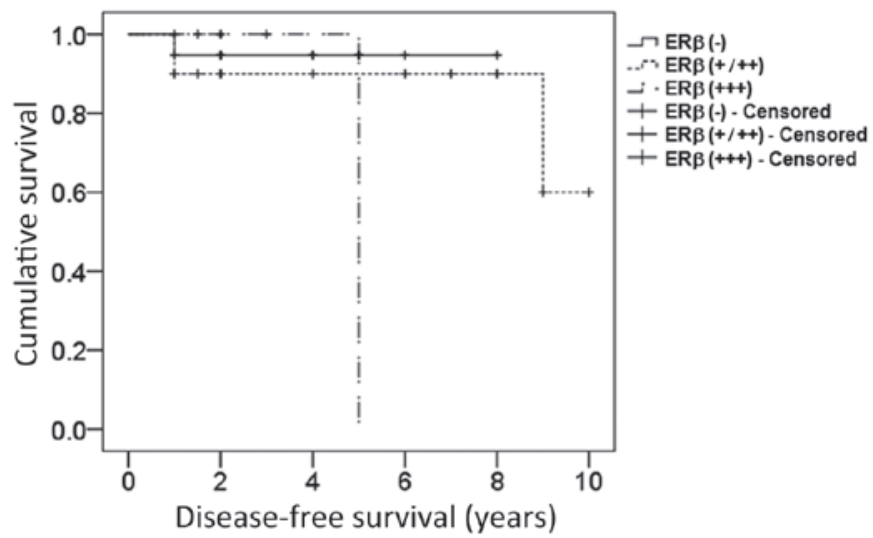

Figure 4. Kaplan-Meier survival curve for endocrine therapy-free postmenopausal ER $\alpha$-positive breast cancer patients exhibiting varying expression levels of ER $\beta$. Disease-free survival was analyzed using the Kaplan-Meier method in 55 patients. An ER $\beta$-positive rate $<1 \%$ was recognized as ER $\beta(-)$, between $1-70 \%$ as $\operatorname{ER} \beta(+/++)$ and $>70 \%$ as $\operatorname{ER} \beta(+++)$. The data from 12 patients were censored due to mortality, loss to follow-up or closure of the study. ER, estrogen receptor.

patients without endocrine therapy. To further clarify the specific influence of ER $\beta$ expression on endocrine therapy in postmenopausal breast cancer, the association between ER $\beta$ expression levels and disease-free survival rate or prognosis in breast cancer patients without endocrine therapy was investigated. The results suggested that the expression levels of ER $\beta$ were not statistically correlated with disease-free survival of postmenopausal breast cancer patients without endocrine therapy (log-rank test, 2.291; P=0.102; Fig. 4). Cox regression analysis indicated that neither clinical stage, chemotherapy, radiotherapy or ER $\beta$ expression levels represented independent prognostic risk factors in breast cancer patients not treated with endocrine therapy $(\mathrm{P}=0.496$, $\mathrm{P}=0.990, \mathrm{P}=0.497$ and $\mathrm{P}=0.368$, respectively; Table IV).

\section{Discussion}

ER $\beta$ serves a significant role in the genesis and progression of breast cancer, and expression levels of ER $\beta$ have been observed to be associated with endocrine therapy resistance $(15,16)$. However, whether ER $\beta$ expression causes breast cancer to become more sensitive or resistant to endocrine therapy remains to be elucidated. Chang et al (17) suggested that high mRNA expression of ER $\beta$ may influence the therapeutic effects of endocrine drugs, leading to endocrine therapy resistance. However, Esslimani-Sahla et al (18) revealed that $E R \beta$ overexpression was able to increase the sensitivity of breast cancer to endocrine therapy. In the present study, an immunohistochemical assay was used to assess the expression levels of ER $\beta$ in postmenopausal ER $\alpha$-positive breast cancer patients, and the association between ER $\beta$ expression levels and endocrine therapy efficacy or disease-free survival rate were additionally investigated. The results provided evidence of the significance of $\mathrm{ER} \beta$ expression in the endocrine therapy resistance of breast cancer, and provided experimental data that may be useful for the individualized assessment of endocrine therapy and prognosis in breast cancer patients. 
In the current study, Cox regression analysis was used to assess the effects of clinical stage, chemotherapy, radiotherapy and endocrine therapy on the prognosis of ER $\alpha$-positive breast cancer in postmenopausal patients. The results demonstrated that clinical stage and ER $\beta$ expression levels represented independent prognostic factors for postmenopausal ER $\alpha$-positive breast cancer $(\mathrm{P}=0.001)$ while, for breast cancer patients treated with endocrine therapy, ER $\beta$ overexpression was the only independent prognostic risk factor $(\mathrm{P}=0.003$; $\mathrm{OR}=4.612)$. These findings suggest that ER $\beta$ expression may have a direct impact on ER $\alpha$-positive breast cancer prognosis in patients treated with endocrine therapy, and ER $\beta$ overexpression may lead to endocrine therapy resistance. Chung et al (19) revealed that the expression levels of ER $\beta$ may affect the transcription of certain genes. Downregulated ER $\beta$ expression modulates cell cycle- and apoptosis-associated genes via the transforming growth factor- $\beta$ signaling pathway, and inhibits cell proliferation-associated genes (20). This indicates that ER $\beta$ expression represents a risk factor during the carcinogenesis of breast cancer. In agreement with this, Park et al (21) identified that ER $\beta$ expression levels were negatively associated with the histological grading of breast cancer, and ER $\beta$ overexpression indicated poor prognosis for breast cancer patients. In the present study, the results from the patient group without endocrine therapy suggested there was no significant association between ER $\beta$ expression levels and the disease-free survival rate of breast cancer patients $(\mathrm{P}=0.205)$. Cox regression analysis revealed that clinical stage, postoperative chemotherapy, radiotherapy and ER $\beta$ expression levels were not significantly associated with disease prognosis, indicating that ER $\beta$ expression levels were not a prognostic factor for breast cancer patients not treated with endocrine therapy. Based on the above results, ER $\beta$ may represent an independent prognostic factor for ER $\alpha$-positive breast cancer patients treated with endocrine therapy. It is thus proposed that, in ER $\alpha$-positive postmenopausal breast cancer patients, ER $\beta$ may influence breast cancer prognosis via affecting endocrine therapy efficacy, and its overexpression is closely correlated with endocrine therapy resistance. However, in order to achieve a definite conclusion, additional evidence from postmenopausal breast cancer patient samples not treated with endocrine therapy is required.

In conclusion, ER $\beta$ overexpression resulted in endocrine therapy resistance and poor prognosis in postmenopausal $\mathrm{ER} \alpha$-positive breast cancer patients treated with endocrine therapy, which suggested that ER $\beta$ may be useful as an indicator for the assessment of endocrine therapy efficacy. ER $\beta$ expression evaluation may provide evidence for whether certain breast cancer patients are suitable for endocrine therapy and may be used as an indicator of individual endocrine therapy efficacy.

\section{Acknowledgements}

The present study was supported by the Natural Science Foundation of Xinjiang Uygur Autonomous Region (grant no. 2011211A069) and the National Clinical Key Subject-General Surgery Construction Project (grant no. 2100299).

\section{References}

1. De Coster S, van Leeuwen DM, Jennen DG, Koppen G, Den Hond E, Nelen V, Schoeters G, Baeyens W, van Delft JH, Kleinjans JC and van Larebeke N: Gender-specific transcriptomic response to environmental exposure in Flemish adults. Environ Mol Mutagen 54: 574-588, 2013.

2. Bergan HE, Kittilson JD and Sheridan MA: PKC and ERK mediate GH-stimulated lipolysis. J Mol Endocrinol 51: 213-224, 2013.

3. Nair HB, Perla RP, Kirma NB, Krishnegowda NK, Ganapathy M, Rajhans R, Nair SS, Saikumar P, Vadlamudi RK and Tekmal RR: Estrogen receptor-beta mediates the protective effects of aromatase induction in the MMTV-Her-2/neu $\mathrm{x}$ aromatase double transgenic mice. Horm Cancer 3: 26-36, 2012.

4. Ali S and Coombes RC: Estrogen receptor alpha in human breast cancer: Occurrence and significance. J Mammary Gland Biol Neoplasia 5: 271-281, 2000.

5. Omoto Y, Inoue S, Ogawa S, Toyama T, Yamashita $H$, Muramatsu M, Kobayashi S and Iwase H: Clinical value of the wild-type estrogen receptor beta expression in breast cancer. Cancer Lett 163: 207-212, 2001.

6. Roger P, Sahla ME, Mäkelä S, Gustafsson JA, Baldet P and Rochefort H: Decreased expression of estrogen receptor beta protein in proliferative preinvasive mammary tumors. Cancer Res 61: 2537-2541, 2001.

7. Hayashi SI, Eguchi H, Tanimoto K, Yoshida T, Omoto Y, Inoue A, Yoshida $\mathrm{N}$ and Yamaguchi Y: The expression and function of estrogen receptor alpha and beta in human breast cancer and its clinical application. Endocr Relat Cancer 10: 193-202, 2003.

8. Fox EM, Davis RJ and Shupnik MA: ERbeta in breast cancer - onlooker, passive player, or active protector? Steroids 73: 1039-1051, 2008

9. Edge SB, Byrd DR, Compton CC, et al (eds): Breast. In: AJCC cancer staging manual. 7th edition. Springer, New York, NY, pp347-376, 2010.

10. Osborne CK and Schiff R: Mechanisms of endocrine resistance in breast cancer. Annu Rev Med 62: 233-247, 2011.

11. Mestron A, Webb SM, Astorga R, et al: Epidemiology, clinical characteristics, outcome, morbidity and mortality in acromegaly based on the Spanish Acromegaly Registry (Registro Espanol de Acromegalia, REA). Eur J Endocrinol 151: 439-446, 2004.

12. Li SL and Chen XP WK: The biological characteristics and clinical treatments of breast cancer. (SL L (ed.)). Science Press, Beijing, 2004.

13. Hammond ME, Hayes DF, Wolff AC, Mangu PB and Temin S: American society of clinical oncology/college of american pathologists guideline recommendations for immunohistochemical testing of estrogen and progesterone receptors in breast cancer. J Oncol Pract 6: 195-197, 2010.

14. Guideline Recommendations for HER2 Detection in Breast Cancer Group: Guidelines for HER2 detection in breast cancer, the 2009 version. Zhonghua Bing Li Xue Za Zhi 38: 836-840, 2009 (In Chinese).

15. Yager JD and Davidson NE: Estrogen carcinogenesis in breast cancer. N Engl J Med 354: 270-282, 2006.

16. Chaves VE, Júnior FM and Bertolini GL: The metabolic effects of growth hormone in adipose tissue. Endocrine 44: 293-302, 2013.

17. Chang HG, Kim SJ, Chung KW, Noh DY, Kwon Y, Lee ES and Kang HS: Tamoxifen-resistant breast cancers show less frequent methylation of the estrogen receptor beta but not the estrogen receptor alpha gene. J Mol Med (Berl) 83: 132-139, 2005.

18. Esslimani-Sahla M, Simony-Lafontaine J, Kramar A, Lavaill R, Mollevi C, Warner M, Gustafsson JA and Rochefort H: Estrogen receptor beta (ER beta) level but not its ER beta cx variant helps to predict tamoxifen resistance in breast cancer. Clin Cancer Res 10: 5769-5776, 2004.

19. Chung YL, Sheu ML, Yang SC, Lin CH and Yen SH: Resistance to tamoxifen-induced apoptosis is associated with direct interaction between Her2/neu and cell membrane estrogen receptor in breast cancer. Int J Cancer 97: 306-312, 2002.

20. Mosselman S, Polman J and Dijkema R: ER beta: Identification and characterization of a novel human estrogen receptor. FEBS Lett 392: 49-53, 1996.

21. Park BW, Kim KS, Heo MK, Ko SS, Hong SW, Yang WI, Kim JH, Kim GE and Lee KS: Expression of estrogen receptor-beta in normal mammary and tumor tissues: Is it protective in breast carcinogenesis? Breast Cancer Res Treat 80: 79-85, 2003. 